was lower than that used in the above myopathy case report $\left(720 \mathrm{mg} / \mathrm{m}^{2}\right.$ daily). Moderate elevations in CK levels are to be expected with zidovudine therapy, and muscle biopsy and EMG may be reserved for children with clinical myopathy or markedly elevated CK levels.

\title{
GUILLAIN-BARRE SYNDROME: AGE VARIATIONS
}

The medical records of 83 children with Guillain-Barre Syndrome were reviewed with reference to the age associated changes at the Department of Pediatrics, University of Tokyo, Japan. Children between 3 and 9 years were most susceptible and summer was the most common time of onset. Limb pain was the initial symptom for $53 \%$ of all patients and for $24 \%$ in the younger age group $(\mathrm{P}<0.05)$. Muscle weakness was the most frequent initial symptom in the younger age group. Upper respiratory infections were the most common preceding illnesses; the interval between the previous illness and the onset of disease was significantly shorter for the older age group. The total duration of the illness was shorter in older children. Cranial nerve involvement occurred in $1 / 3$ of children under 5 years of age and in the same proportion of children over 5 years. In the younger age group bulbar nerves were most commonly affected whereas the facial nerve was involved most frequently in the older age group. Patients with cranial nerve involvement suffered more frequently from respiratory insufficiency; the ages of those affected were distributed evenly between the two groups. The differences in initial symptoms and in interval between preceding illnesses and onset of the disease seemed to be related to the maturational processes of peripheral nerve and spinal root ganglia. It is speculated that the stage of the myelinogenic process might be important in the explanation of age associated alterations in symptomatology (Sakakihara Y, Kamoshita S. Age associated changes in the symptomatology of Guillain-Barre syndrome in children. Dev Med Child Neurol July 1991; $\underline{33}: 611-616)$.

COMMENT. The incidence of Guillain-Barre Syndrome increases with age but $25 \%$ of cases occur in childhood and adolescence. Since nerve conduction velocity and the thickness of the myelin sheath in peripheral nerves reaches adult levels at around five years of age, some variation in symptomatology between young and older children might be expected. Electrodiagnostic tests have been shown to corroborate the neuropathologic sequence in the Guillain-Barre Syndrome and these findings may be modified by age and maturation (Ropper $\mathrm{AH}$ et al. Arch Neurol 1990; 47:367; McFarland HR Arch Neurol July 1991; $\underline{48}: 678)$

\section{DEVELOPMENTAL DISORDERS}

\section{LISSENCEPHALY: CLINICAL AND MRI FINDINGS}

Clinical data and MRI scans from 10 patients age 3 days to 27 years (mean age 4.6 years) with lissencephaly were reviewed in the Departments of Radiology, Neurology and Pediatrics, University of California, San Francisco, 